\title{
In situ testing and modeling of cultural heritage buildings in Peru
}

\author{
P.B. Lourenço, G. Karanikoloudis \& F. Greco \\ ISISE, Department of Civil Engineering, University of Minho, Guimarães, Portugal
}

\begin{abstract}
This paper provides the results of in situ testing and modelling of four case studies in Peru and is part of the ongoing Seismic Retrofitting Project, under the auspices of the Getty Conservation Institute (GCI): Casa Arones (Cusco), Hotel Comércio (Lima), Ica Cathedral (Ica) and Kuño Tambo (Acomayo). These are mostly earthen buildings made with adobe, with the presence of large amounts of timber and, in some cases, brick masonry and rubble stone masonry (mostly for the base course in contact with the ground). In situ testing consist of an extensive sonic testing campaign and dynamic identification. Advanced modeling of two case studies allowed demonstrating that these structures have a high vulnerability and require strengthening measures.
\end{abstract}

\section{INTRODUCTION}

Adobe is one of the oldest and most widely used natural materials in construction. The overall seismic performance and corresponding seismic vulnerability of masonry and adobe buildings in general is highly related to the level of redistribution of the seismic loads in between the elements, enhanced by connections, stiff floors or ring beams and joists, which provide a diaphragmatic structural response, also known as "box behavior". Adobe historic buildings often lack confinement, thus resulting in loss of connectivity and structural isolation of individual elements, which under seismic loading become susceptible to out of plane failure modes.

The present work is part of the Seismic Retrofitting Project (SRP), a component of the Getty Conservation Institute's Earthen Architecture Initiative. The SRP seeks to combine traditional construction techniques and materials with high-tech methodologies to design and test easy-to-implement seismic retrofitting techniques and maintenance programs to improve the structural performance and safety of earthen buildings while minimizing loss of historic fabric.

This paper provides results of in situ testing and modelling of the four case studies: Casa Arones (Cusco), Hotel Comércio (Lima), Ica Cathedral (Ica) and Kuño Tambo (Acomayo). With the exception of the latter, these buildings incorporate a significant portion of timber components. In situ testing consist of an extensive sonic testing campaign and dynamic identification, allowing obtaining indirect measurements of the elastic mechanical properties of the masonry-like materials and validation of the numerical models. Then, advanced modeling was adopted for the assessment of the seismic safety.

\section{IN SITU TESTING}

\subsection{Survey details}

The survey took place from the 23rd of May to the 6th of June 2015, with the objective to gather additional information for the structural analysis of these buildings. The task of creating accurate numerical models of historical buildings is quite challenging due to the unknown parameters, such as materials properties, construction technologies and morphology. Documentation from previous inspections, surveys and testing of material properties were already available from Cancino et al. (2012). In this context, part of the current campaign was used to collect additional information related to the damage identification and to the geometrical survey needed for creating the models. Moreover, an additional photographical survey was performed during the visits. In particular, attention was paid to the survey of the timber structure of the Ica Cathedral in order to be able to understand the details of this complex mixed masonry-timber structure.

The overall behavior of the buildings has been characterized by performing identification tests in order to try to provide their dynamic characteristics using the ambient vibration as a source of excitation. This type of test has been performed in the Church of Kuño Tambo, in the Cusco Region, and in the Cathedral of Ica, in the Ica Region. The same test for the Hotel el Comercio was already available, Aguilar et al. (2013). Casa Arones has been found abandoned, partly collapsed, partly under reconstruction and partly used for storage. The existing condition, the complexity of the structure and the extensive presence of temporary shoring made the case study less suited for dynamic identification, and a decision was made not to adopt this investigation technique. 
The mechanical properties of selected materials composing the structural part of the four structures were also characterized using sonic test equipment. In particular, the base course and adobe or brick masonry have been recurrently tested and, in Casa Arones, also the stone was tested. Full details can be found in Greco et al. (2015).

\subsection{Dynamic identification testing}

The objective of the dynamic identification tests was to determine the natural frequencies, the mode shapes and the damping ratios of the structures. The validation of the dynamic properties, which are directly related with mechanical and structural characteristics (namely stiffness, mass, connectivity between members and boundary conditions), allows better interpreting the structural behavior of historic structures, which are often highly complex and mechanically diverse.

The equipment used during the tests consists of piezoelectric accelerometers with a sensitivity of $10 \mathrm{~V} / \mathrm{g}$ and a frequency range of 0.15 to $1000 \mathrm{~Hz}$ (measurement range $\pm 0.5 \mathrm{~g}$ ). These were connected to a data acquisition board of 24-bit resolution, which has the function to record the signals given by the accelerometers. The results obtained were then processed in ARTeMIS software. The dynamic properties obtained with a time domain method, the Stochastic Subspace Identification Method (SSI), Peeters and De Roeck (1999), are shown next.

\subsubsection{Kuño Tambo church}

Tests were carried out in four setups with one reference accelerometer and three accelerometers in each setup. The chosen monitoring points were in the top parts of the lateral walls of the nave, in the gable ends of the north and south façade of the nave, as well as in the gable wall of the baptistery, see Figure 1). The position of the reference accelerometer, close to the middle span of the west lateral wall of the nave, was chosen based on the preliminary modal analyses, which revealed a high amplitude of displacement in that area.

The poles selection and the link of modes from all four setups obtained using the SSI method is presented in Figure 2. The vertical lines indicate the frequencies of the identified modes for different model orders, which can be reliably considered.

The first four modes were defined and the frequencies and damping ratios for each method were obtained, see Figure 3. As can be seen from the configuration of the mode shapes, the structure seems not to have global modes involving continuity of the different parts. The dynamic response is characterized by the absence of box behavior, with lack of connection between the lateral and gable walls, and between the walls and roof. This lack of connection can be associated with the visible cracks close to the corners. Thus, each wall seems to be excited mostly independently, with mode shapes similar to those of a cantilever beam. Note that the measuring points' resolution is low, given the time constraints.

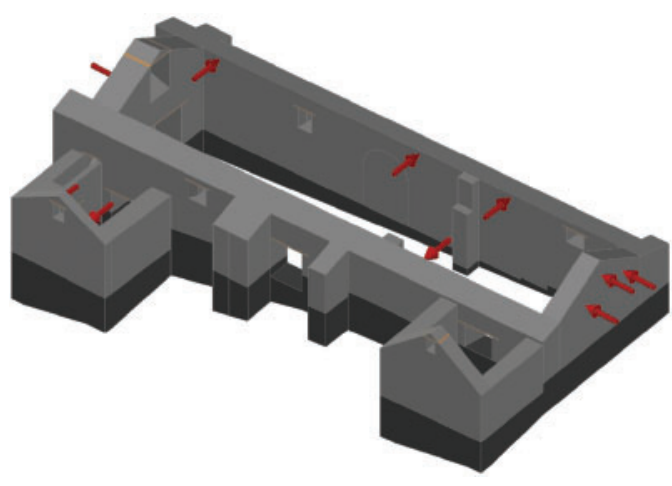

Figure 1. Disposition of accelerometers in the performed setups at the nave and baptistery walls.

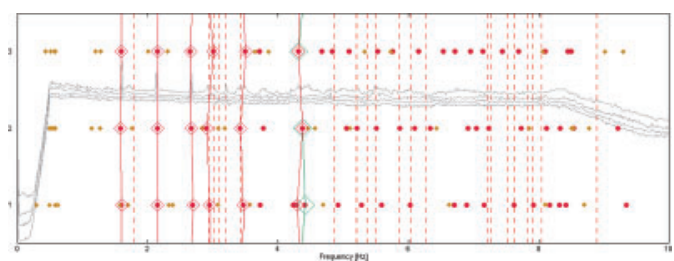

Figure 2. Data driven with the poles selection through the several test setups of the SSI method.
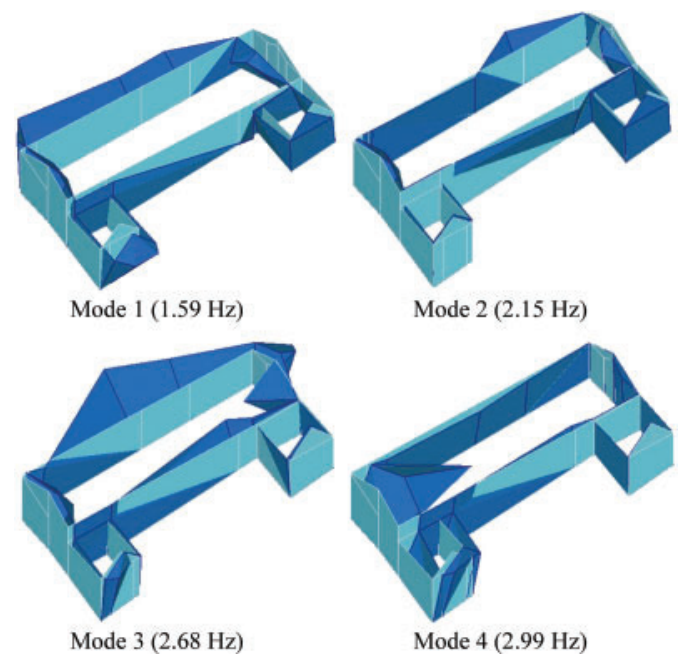

Figure 3. Mode shapes obtained from the SSI Method, of the first four modes, with interpolation.

Mode 1 corresponds to the first mode in the transversal direction of the nave. Both the lateral and gable walls of the nave experience a symmetric 1st order out-of-phase excitation with high amplitudes. In mode 2 , the configuration is similar, except by the fact that the west wall of the nave has a 2 nd order curvature, with a deflection point near the middle span. Mode 3 corresponds to a complex mode, which involves the inphase and out-of-plane excitation of the west wall, with the north façade in a 2 nd order curvature. Lastly, the 


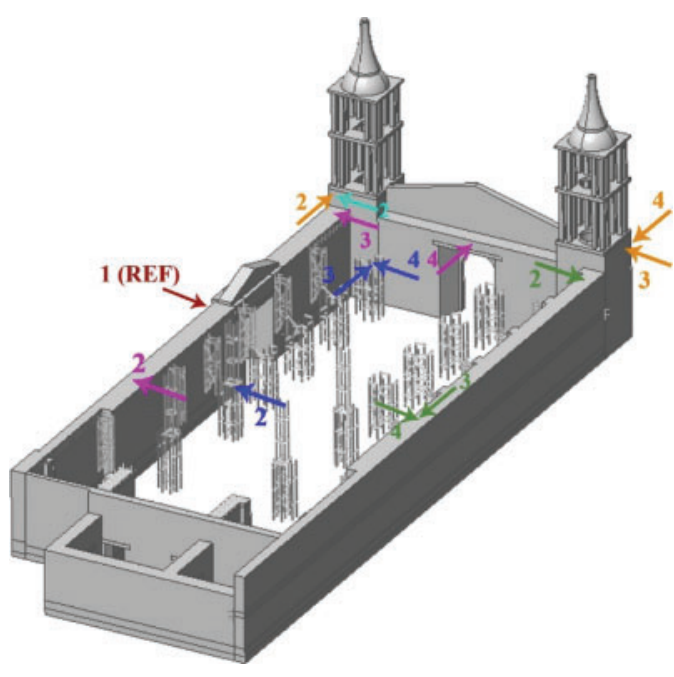

Figure 4. Disposition of accelerometers in the performed setups at the nave and baptistery walls.

mode 4 is mainly characterized by the high amplitude of the out-of-plane deflection of the south façade.

\subsubsection{Ica Cathedral}

Dynamic identification tests were performed in five setups with one reference accelerometer and three accelerometers positioned in the areas of interest. Figure 4 depicts the position of the sensors in each setup. The reference accelerometer was positioned on the top of the longitudinal masonry wall shown.

The selection of poles and the link of modes from the four setups using the SSI methods are presented in Figure 5. The first three modes were analyzed as the higher modes do not have a significant influence on the dynamic behavior of civil engineering structures and the calibration of a numerical model based on several modes is difficult, see Figure 6. Mode 1 corresponds to the 1st mode in the transversal direction of the longitudinal side walls of the Cathedral. Both the longitudinal walls of the nave experience a 1st order out-of-phase excitation with higher intensity in the north wall in the transept area, meaning again that the timber structure seems weakly connected to the masonry structure. Mode 2 identifies the 2 nd order curvature of the north wall, with a deflection point near the middle span, between the two measured points. Mode 3 corresponds to a complex mode, which is mainly characterized by the out-of-plane movement of the main façade.

\subsection{Sonic testing}

Elastic wave methods are well known Non-Destructive Techniques (NDT). The velocity of wave propagation within a solid is proportional to its physical and mechanical properties, namely density, Poisson's ratio and Young's modulus. Due to this, changes in wave velocity indicate differences in the quality of the inner layer of the material, Binda et al. (2001).

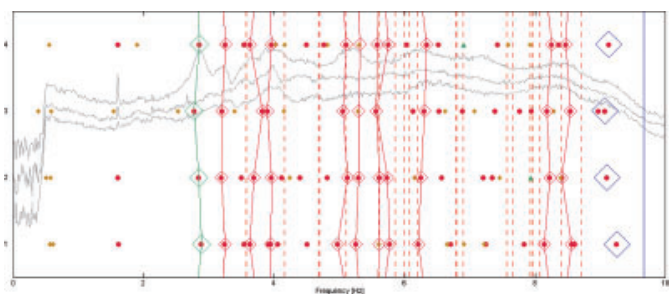

Figure 5. Data driven with the poles selection through the several test setups of the SSI method.

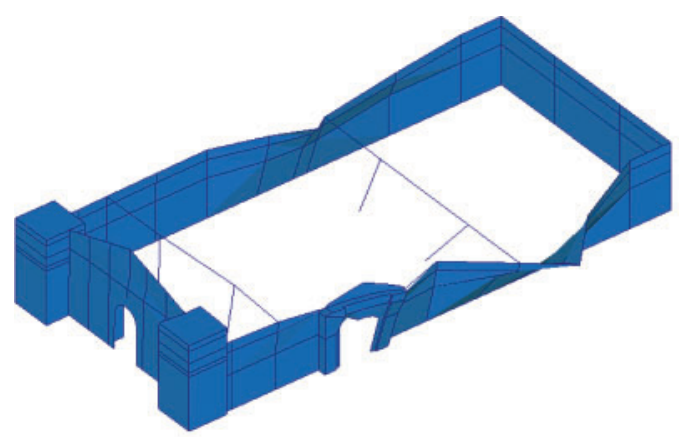

Mode $1(2.84 \mathrm{~Hz})$

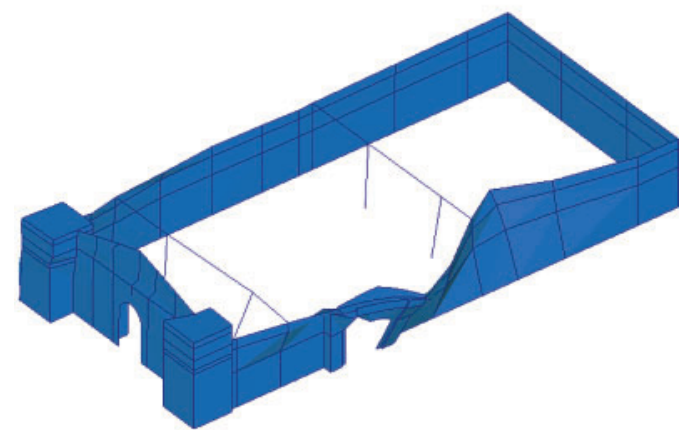

Mode $2(3.22 \mathrm{~Hz})$

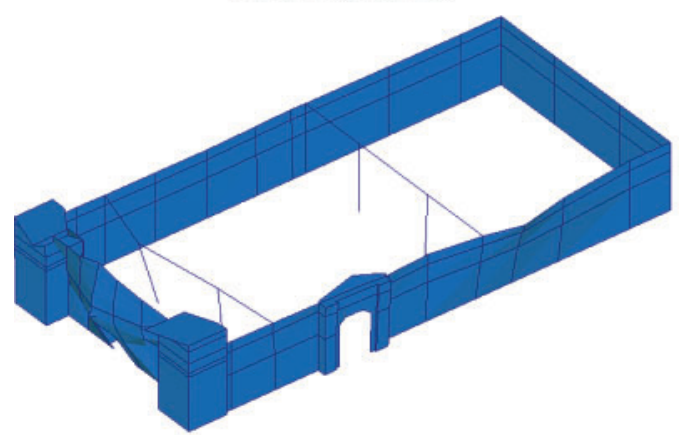

Mode $3(3.94 \mathrm{~Hz})$

Figure 6. Mode shapes obtained from the SSI Method, of the first three modes, with interpolation.

The equipment used for the execution of the sonic tests consists of one accelerometer $(+/-0.5 \mathrm{~g}$, $10 \mathrm{~V} / \mathrm{g})$, one instrumented hammer $(22240 \mathrm{~N} \mathrm{pk})$, a personal computer, a data acquisition system (National 

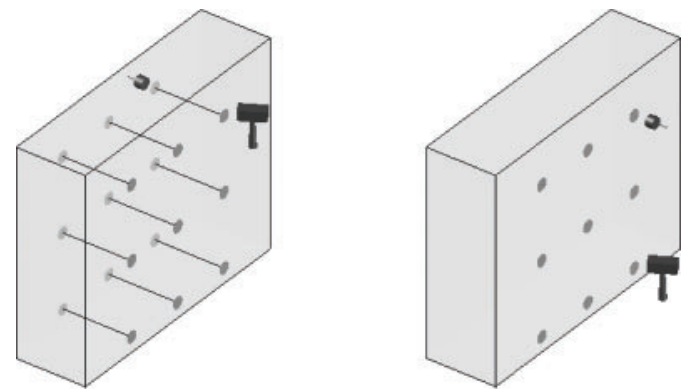

Figure 7. Relative position of the hammer and accelerometer: direct sonic test (left); indirect sonic test (right).

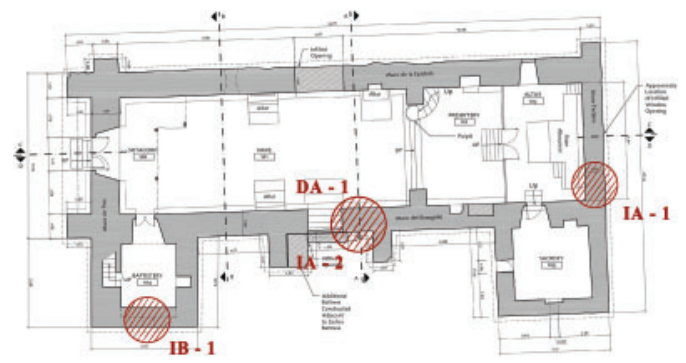

Figure 8. Locations of the sonic tests in Kuño Tambo Church.

Instruments), and cables. The velocity of propagation of the waves can be obtained by identifying the time between the emission of the signal and its reception. Sonic tests can be performed in different ways depending on the position of the accelerometer and the hammer (Figure 7).

The location of the sonic tests has been made considering multiple factors, such as easy accessibility to a sufficient large are of wall, absence of plaster so that tests are carried out in the masonry itself, possibility to carry our direct tests, absence of severe material deterioration and cracking, and available time to carry out the tests Still, it is noted that this information is complemented with tests on similar materials in Peru, literature review of material properties and the dynamic identification tests, which, when coupled with a numerical model, provide also an estimate of elastic properties.

Note also that, for the purpose of structural analysis, the sensitivity of the response to reasonable changes in the elastic properties will affect the results marginally.

As an example, the locations of the tests performed in Kuño Tambo Church are shown in Figure 8. Indirect sonic tests corresponding to the codes IA -1 and IA -2 have been performed on adobe masonry walls of the east wall and of the north façade. Due to the presence of paintings in the interior of the Church as well as the different level between the interior and exterior, just one direct test was possible (DA - 1) corresponding to the same grid of the one defined for the test IA -2 . Finally, the base course has been tested (IB - 1) with
Table 1. Results of the direct sonic tests.

\begin{tabular}{lllll}
\hline Case study & $\begin{array}{l}V_{P} \\
(\mathrm{~m} / \mathrm{s})\end{array}$ & $\begin{array}{l}\mathrm{CoV} \\
(\%)\end{array}$ & $\begin{array}{l}V_{R} \\
(\mathrm{~m} / \mathrm{s})\end{array}$ & $\begin{array}{l}E_{d} \\
(\mathrm{MPa})\end{array}$ \\
\hline KT / Adobe & 380 & $7 \%$ & 210 & 0.25 \\
CA / Adobe & 840 & $18 \%$ & 470 & 1.20 \\
\hline
\end{tabular}

Table 2. Results of the indirect sonic tests.

\begin{tabular}{llrrl}
\hline Case study & $\begin{array}{l}V_{R} \\
(\mathrm{~m} / \mathrm{s})\end{array}$ & $\begin{array}{l}\mathrm{CoV} \\
(\%)\end{array}$ & \multicolumn{1}{l}{$\begin{array}{l}V_{P} \\
(\mathrm{~m} / \mathrm{s})\end{array}$} & $\begin{array}{l}E_{d} \\
(\mathrm{MPa})\end{array}$ \\
\hline KT / Adobe 1 & 230 & $6 \%$ & 410 & 0.29 \\
KT / Adobe 2 & 220 & $7 \%$ & 390 & 0.26 \\
HC / Adobe & 370 & $23 \%$ & 660 & 0.75 \\
$\mathrm{CA} /$ Adobe 1 & 410 & $16 \%$ & 730 & 0.92 \\
$\mathrm{CA} /$ Adobe 2 & 340 & $19 \%$ & 610 & 0.63 \\
IC / New Adobe & 360 & $18 \%$ & 650 & 0.72 \\
KT / Base Course & 540 & $36 \%$ & 960 & 1.59 \\
HC / Brick 1 & 450 & $12 \%$ & 800 & 1.08 \\
HC / Brick 2 & 570 & $10 \%$ & 1010 & 1.75 \\
HC / Brick 3 & 480 & $9 \%$ & 850 & 1.24 \\
IC / New Brick & 720 & $6 \%$ & 1290 & 2.86 \\
\hline
\end{tabular}

indirect sonic tests on the exterior side of the baptistery wall, on the east side of the Church.

The results of the tests are shown in Table 1 and Table 2. Here, $V_{P}$ is the average velocity of the $\mathrm{P}$ (compressional or primary) waves, $\mathrm{CoV}$ is their coefficient of variation for a given location, $V_{R}$ is the average velocity of the $\mathrm{R}$ (Rayleigh or surface) waves, $E_{d}$ is the dynamic Young's Modulus, KT means Kuño Tambo, CA means Casa Arones, HC means Hotel el Comercio and IC means Ica Cathedral. In general the $\mathrm{CoV}$ are low, indicating reliable measures. The average $E_{d}$ found for adobe and brick masonry is $0.57 \mathrm{GPa}$ and $1.36 \mathrm{GPa}$, respectively.

\section{MODELING}

\subsection{Modeling details}

The four case studies have been modeled in order to understand damage, evaluate seismic safety and define remedial measures. The results of two of the case studies (under current conditions) are briefly described next and fully detailed in Karanikoloudis and Lourenço (2015) and Lourenço et al. (2015). Modeling of the other two case studies is being finalized. The material properties were determined from technical building standards (US FEMA 306, US ASCE 41-13, Italian NTC 2008 and European EN 1996-1-1), considering also the results of the experimental campaign conducted in the Seismic Retrofitting Project, including the in situ sonic testing reported above. Different materials are defined, such as adobe, brick and rubble stone masonry, and different types of timber.

The inelastic behavior of masonry involves a decrease of the mechanical resistance leading to 
failure. The physical nonlinear compressive and tensile behavior of masonry is described through a total strain rotating crack model, see DIANA (2014), in which tensile stresses can be assumed to diminish exponentially, while compression combines a hardening and a softening phase.

The progression of tensile and compressive damage and the corresponding lateral capacity, as well as global or local failure modes of the building were evaluated by applying a mass proportional lateral load. In total, four pushover analyses were conducted, with the lateral loads applied in the $\mathrm{x}-\mathrm{x}$ and $\mathrm{y}-\mathrm{y}$ main axes, both in positive and negative directions. The structural response was assessed from load displacement curves, in control points of maximum recorded horizontal displacements and the failure modes were identified at ultimate stage using principle tensile strains and crack widths.

\subsubsection{Kuño Tambo church}

A 3D finite element model was built in DIANA software, according to the generated 3D CAD model. The model includes the nave, with the adjoining buttresses, the sacristy and baptistery, the corresponding base course foundation, with its differences in elevation, and the system of timber ties and anchors. Two sets of material properties were defined, regarding the Young's Modulus, a more conservative one taken from literature (Model GM1) and the other from the in situ sonic test campaign (Model GM2), which provided a difference in capacity of about $20 \%$ (the lowest value is assumed here).

The system of tie beams and their connection with the adobe walls of the nave can have a significant effect on the transversal behavior of the structure. Under the current condition, given the visual inspection and the results of the dynamic identification tests, the system of ties is considered inactive.

The results in terms of maximum principal strain at failure are shown in Figure 9 at collapse. One of the structural deficiencies of the church is large asymmetric distribution of stiffness in the transverse direction of the nave. The aligned walls and buttresses of the east part, when activated through diagonal compression, have a stiffer response and a larger lateral capacity.

The failure mode with the lowest capacity, the outof-plane overturning of the west lateral wall, controls the response, and the obtained minimum value is $0.19 \mathrm{~g}$. According to the pushover analyses, strengthening in needed in multiple directions, since the overall capacity does not reach the peak ground acceleration for the region $(0.30 \mathrm{~g})$.

The weakest directions, with very low lateral capacity for the structure without ties are the east-west direction (+YY) and the south-north direction (+XX). Karanikoloudis and Lourenço (2015) showed that with the usage of an adequate tying system, the capacity of the structure in east-west direction (+YY) is significantly increased but the same does not happen in the south-north direction $(+\mathrm{XX})$, where the adequacy of remaining partly destroyed buttressing walls (not
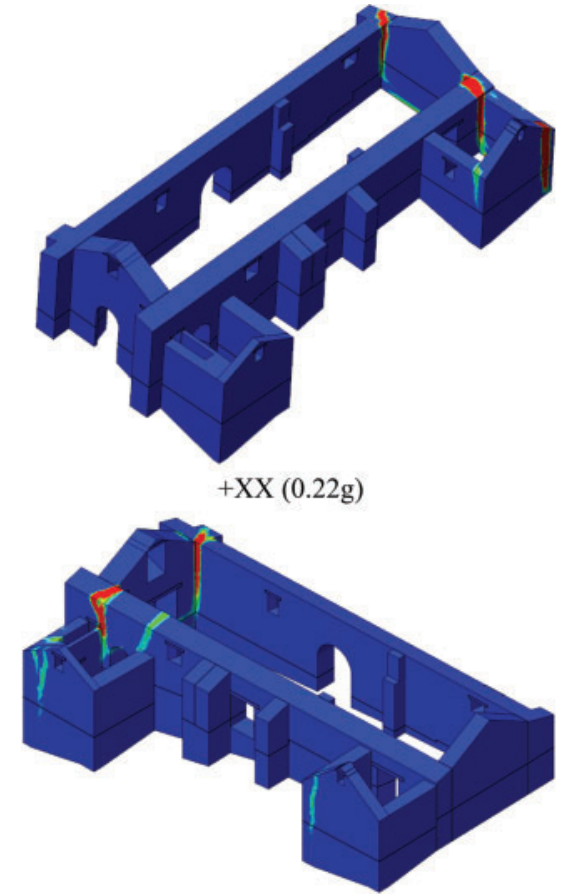

$-\mathrm{XX}(0.28 \mathrm{~g})$

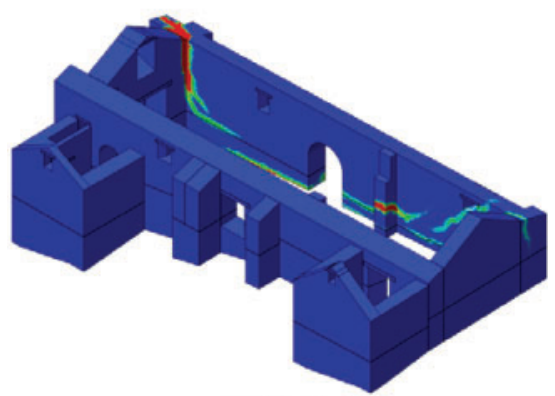

$+\mathrm{YY}(0.19 \mathrm{~g})$

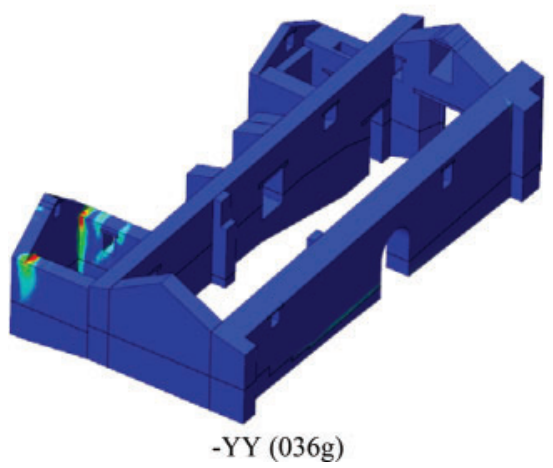

Figure 9. Distribution of maximum principal tensile strains at ultimate stages for different loading directions (red indicates maximum crack opening). The capacity of structure (measured by a percentage of the mass horizontally applied is also shown). 
considered in the model), and their connection to the church, must be addressed.

The possible reintroduction of the buttresses in the west lateral wall will increase the stiffness in the west part and will much positively contribute to the behavior of the nave and will increase the global capacity of the structure. The connection of the ties to the walls should be reestablished, ensuring adequate behavior in tension and compression by using a larger cross section and anchor keys/embedded timber trusses, and two new ties should be possibly added to reduce the large spacing between existing ties. New ties should also be inserted at the top of the baptistery and sacristy sidewalls, in order to limit out-of-plane local collapse modes. The connectivity in the intersections between walls can also be enhanced with the use of corner keys, which can stiffen the gable walls and prevent out-ofplane collapse modes. Such corner keys can be placed in the corners of the north gable wall, the baptistery and sacristy.

\subsubsection{Ica Cathedral}

A structural analysis was initially performed on the representative timber bay of Ica Cathedral under vertical and lateral loads. Moreover, the influence of the timber connections was investigated and the most critical joints are identified using a representative bay. Considering the self-weight, live load and earthquake load the compliance with the various criteria specified by Eurocode 5 was evaluated by performing global and local verifications on the timber members and connections.

The 3D finite element model of the representative bay is constructed in SAP 2000 structural and earthquake engineering software, CSI (2014), after the Autocad drawing show in Figure 10. The deformed mesh under self-weight is shown in Figure 11.

For the ultimate limit states (ULS) under vertical load, the verifications are satisfied for all the timber elements of the representative bay. Under earthquake load combination the verification is satisfied for all the transversal and the longitudinal beams above pillars and pilasters. On the other hand, the beams at the top of the lunettes are not verified. In addition, while all the posts of the nave pillar are verified, the posts of the pilaster which are closer to the masonry wall are not verified for stability. The result obtained from the verification for ULS under earthquake load combination seems in agreement with the damage observed after the earthquakes.

According to the obtained results from the local verification for ULS under earthquake load combination, the stresses that occur in correspondence to the mortise and tenon connections of the beams at the top of the lunettes are large enough to provoke the failure of the structure, as verified during the earthquakes.

A 3D finite element model of the masonry structure of Ica Cathedral in its current state was constructed in Midas FX+ Version 3.3.0 Customized Pre/Post processor for DIANA software. Tthe model includes the

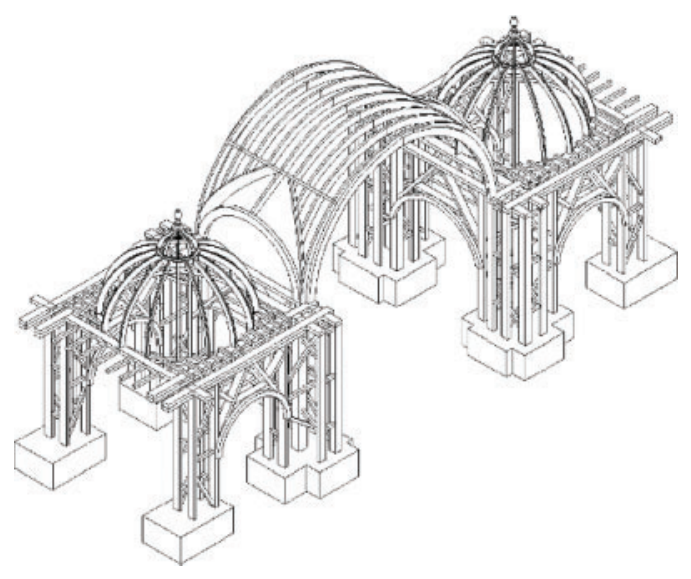

Figure 10. 3D architectural AutoCAD model.

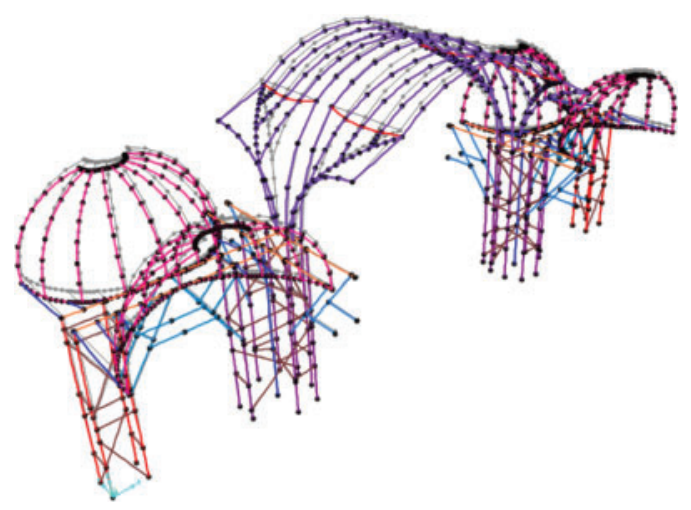

Figure 11. Deformed shape of the structure under self-weight.

fired brick masonry façade, the bell towers, the northern and southern lateral walls and it stops at the altar with the adjoining lateral chapels. The building parts housing the sacristy, reception and offices are not included in the model as from the visit conducted during May 2015, Greco et al. (2015), they were observed to be new structures with light weight roofing systems, not acting as a part of the masonry envelope. The results of the dynamic identification tests, also show that the timber internal structure and masonry envelop are working, mostly, in an independent way. Still, a model with the results of the full structure is available in Lourenço et al. (2015). Here, only the results for the masonry envelop will be shown.

The results in terms of maximum principal strain at failure are shown in Figure 12 at collapse. From the pushover analyses performed, it can be concluded that the masonry envelope has a better seismic performance in the XX direction of the numerical model than YY direction, as expected. Transversal directions are usually the weakest in this type of buildings. The minimum capacity of the masonry structure is in the $-Y Y$ direction of the numerical model, which is a value of $0.18 \mathrm{~g}$, which is the controlling failure load 

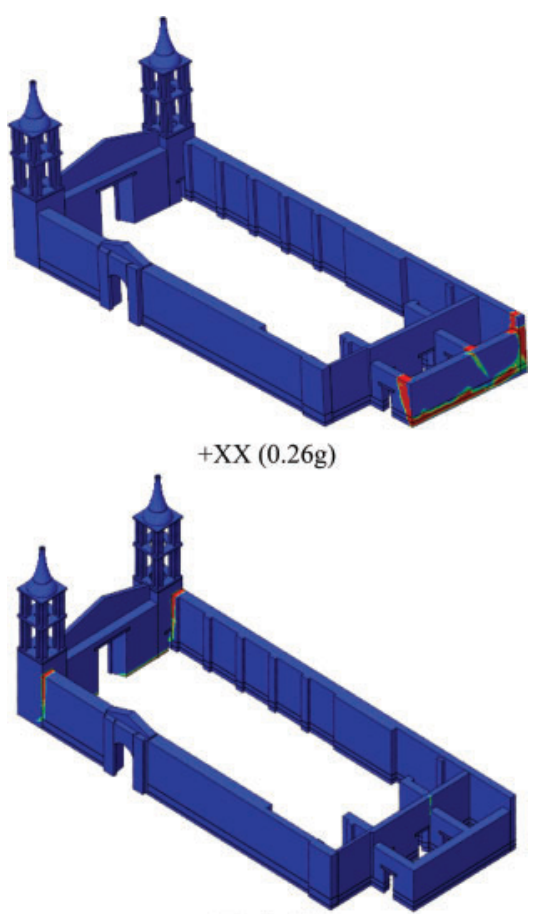

$-\mathrm{XX}(0.33 \mathrm{~g})$

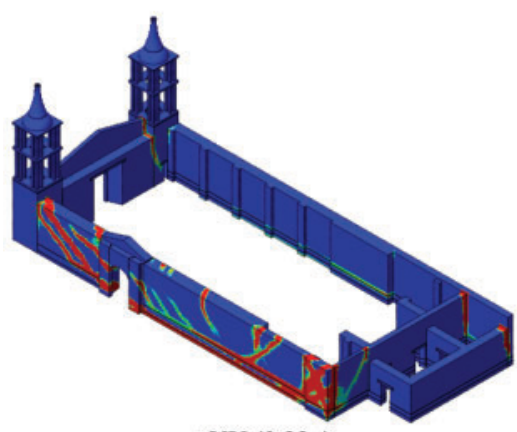

$+\mathrm{YY}(0.22 \mathrm{~g})$

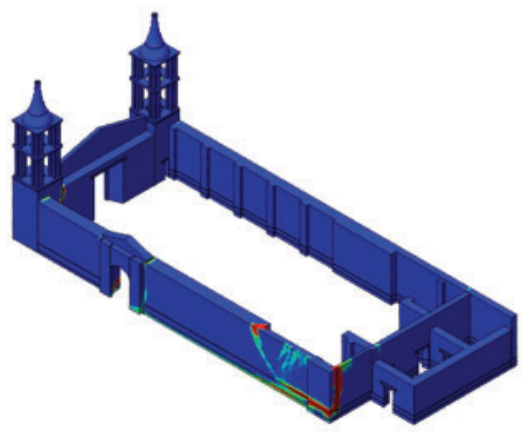

$-\mathrm{YY}(018 \mathrm{~g})$

Figure 12. Distribution of maximum principal tensile strains at ultimate stages for different loading directions (red indicates maximum crack opening). The capacity of structure (measured by a percentage of the mass horizontally applied is also shown). and mechanism. This value is much lower than the PGA considered in the code for the region $(0.40 \mathrm{~g})$.

A good correlation of damage observed in-situ due to the Pisco earthquake of 2007 and in the numerical model is noticed. It can be concluded reasonably that the FEM model is representing well the global response of the structure. The failure modes in all the directions of the numerical model involves the development of flexural cracks at the base course of the masonry envelope. The integration of the two substructures (timber and masonry) in a combined model provided an increase in seismic capacity of about $25 \%$ in both orthogonal directions, when comparing the complete timber and masonry structure with respect to only the masonry envelope. As the timber structure is rather complex and the connections between the two structures play a relevant role in the response, this strength increase must be considered with much precaution.

Global strengthening is therefore required and needs to address the most vulnerable region of the structure identified by the pushover analysis, i.e. the wall near the north-western corner of the Cathedral, as well as other out-of-plane mechanisms. The reduction of the out-of-plane vulnerabilities found might be addressed by tying, additional buttressing, ring beams, proper connections and / or other measures. Ensuring adequate connection between the timber and masonry substructures also provides better global response of the structure.

\section{CONCLUSIONS}

The site visit and experimental campaign on the four buildings of the Getty Seismic Retrofitting Project involved carrying out tests and visual inspection. The results of the campaign were valuable for the definition of the numerical models, clarifying some of the existing doubts.

By performing sonic tests, it was possible define the quality of some of the materials composing the structures and to estimate mechanical parameters. The dynamic identification tests allowed to characterize the elastic behavior of the real structure, allowing to define also global Young's Modulus of the structures and validate the quality of the connections between different structural elements.

The seismic vulnerability of two of the four case studies was addressed using advanced numerical simulations and pushover analyses. The studies aimed at reproducing the existing damage patterns and assessing safety under current condition. Both structures were found to possess very high vulnerability and to need strengthening measures, which have also been implemented and subsequently incorporated in the models. Currently, the safety assessment of these structures after the planned strengthening with traditional local techniques has been completed, discussing in detail the relevance of the timber elements with the complex adobe and timber construction. 


\section{REFERENCES}

Aguilar, R., Ramos, L.F., Torrealva Dàvila, D. \& Chàcara, C. 2013. Experimental Modal Identification of an existent earthen residential building. In L.F. Ramos et al. (ed.), IOMAC' 2013 - 5th International Operational Modal Analysis Conference; Proc. intern. symp., Guimarães, 13-15 May 2013.

Binda, L., Saisi, A. \& Tiraboschi, C., 2000. Investigation procedures for the diagnosis of historic masonries. Construction and Building Materials 14(4): 199-233.

Cancino, C., Lardinois, S., D'Ayala, D., Fonseca Ferreira, C., Torrealva Dàvila, D., Vicente Meléndez, E. \& Villacorta Santamato, L., 2012. Seismic Retrofitting Project: Assessment of Prototype Buildings. Los Angeles: Getty Conservation Institute.

CSI 2014. Analysis Reference Manual for SAP 2000, ETABS, SAFE and CSiBridge, Berkeley.
DIANA 2014. Manuals TNO DIANA. (Available from $\mathrm{http}: / /$ tnodiana.com/DIANA-manuals)

Greco, F., Karanikoloudis, G., Mendes, N., Lourenço, P.B. 2015. Experimental in situ testing campaign on adobe historic structures in Peru, within the Getty SR Project. Report 2015-DEC/E-30. Guimarães: Universidade do Minho.

Karanikoloudis, G. \& Lourenço, P.B. 2015. Seismic Assessment of Kuño Tambo Church, Peru. Report 2015-DEC/E41. Guimarães: Universidade do Minho.

Lourenço, P.B., Sharma, S., Ciocci, M.P. \& Greco, F. 2015. Seismic Assessment of Ica Cathedral, Peru. Report 2015DEC/E-34. Guimarães: Universidade do Minho.

Peeters, B., and De Roeck, G. 1999. Reference-based stochastic subspace identification for output-only modal analysis. Mechanical Systems and Signal Processing 13(6): 855-878. 